\title{
Model Predictive Control for Shunt Active Power Filter in Synchronous Reference Frame
}

\begin{abstract}
A. K. Al-Othman ${ }^{\dagger}$, M. E. AlSharidah*, Nabil A. Ahmed** and Bader. N. Alajmi*
Abstract - This paper presents a model predictive control for shunt active power filters in synchronous reference frame using space vector pulse-width modulation (SVPWM). The three phase load currents are transformed into synchronous rotating reference frame in order to reduce the order of the control system. The proposed current controller calculates reference current command for harmonic current components in synchronous frame. The fundamental load current components are transformed into dc components revealing only the harmonics. The predictive current controller will add robustness and fast compensation to generate commands to the SVPWM which minimizes switching frequency while maintaining fast harmonic compensation. By using the model predictive control, the optimal switching state to be applied to the next sampling time is selected. The filter current contains only the harmonic components, which are the reference compensating currents. In this method the supply current will be equal to the fundamental component of load current and a part of the current at fundamental frequency for losses of the inverter. Mathematical analysis and the feasibility of the suggested approach are verified through simulation results under steady state and transient conditions for non-linear load. The effectiveness of the proposed controller is confirmed through experimental validation.
\end{abstract}

Keywords: Active power filter, Model predictive control, Synchronous reference frame Harmonic compensation, dSPACE controller

\section{Introduction}

Power electronic devices impose nonlinear loads on the ac mains, such as single-phase and three-phase diode rectifiers, thyristor converters and electronic appliances [1]. Aluminum smelter plants and large electrolysis chemical plants, in which large DC rectifiers with high power ratings, are usually used $[2,3]$. They generate considerable amounts of characteristic and non-characteristic harmonics, which will be harmful for other loads connected to the same bus. In such plants, auxiliary control, protection measuring systems and $\mathrm{kWh}$ counters severely suffer from these harmonics [4]. Also, large DC drives used in cement factories or in electric traction application generate enormous harmonics. DC arc furnaces generate several harmonics in the feeding system $[5,6]$. Electrolysis of water and wind mill generators are other examples of harmonic pollution. Many international agencies have implemented firm harmonic restrictions to electronic equipment $[7,8]$. To overcome these problems, classically, passive LC filters are used to eliminate the current harmonics and to improve the power factor. However,

$\dagger$ Corresponding Author: Dept. of Electrical Engineering, College of Technological Studies, Kuwait. (ak.alothman@paaet.edu.kw)

* Dept. of Electrical Engineering, College of Technological Studies, Kuwait. (malshar@gmail.com, bna01@hotmail.com)

** Dept. of Electrical Engineering, College of Technological Studies, Kuwait. (na.ahmed@paaet.edu.kw), on leave from Assiut University, Egypt.

Received: August 15, 2015; Accepted: November 10, 2015 passive LC filters are bulky, load dependent and inflexible $[9,10]$. As a result, a vast number of power factor correction techniques have been developed in compliance with these regulations $[11,12]$. As an alternative, parallel harmonic correction techniques, shunt active power filters (APFs), have been explored by many researchers and considered as a possible solution for reducing current harmonics and improving the power quality [13-14]. The APF is required to generate a matched reactive and harmonic current to compensate for the negative effect of nonlinear loads on the line, thus it handles only the fraction of the total power supplied to the load.

Many articles have been published that focus on obtaining the current reference for three-phase or singlephase APF. Standard APFs configurations require the measurement of both load and filter currents with reference current regulators implemented by hysteresis and PWM modulators. Ozdemir et al. proposed a simplified control algorithm for shunt APF without load and filter current measurement in [15]. In [16], Chen developed a statespace model of the four-leg APF based on $\mathrm{H}$ controller for current tracking from the passivity point of view based on 4-leg VSI. In [17], APF is combined with thyristor switched capacitor for the purpose of reducing cost. A model predictive control (MPC) is presented where Fuzzy model predictive control [18] and neural network predictive control [19] are used in shunt APFs, but the control designs are still complicated. Mohanty evaluates 
the performance of shunt APF for two different control strategies namely hysteresis current control and space vector pulse width modulation [20]. The same concept is used in [21] by Mendalek, where the voltage level of the dc side is regulated using a linearizing feedback control. In [22], Wang developed a simplified MPC method for shunt APFs. Da Silva in [23] proposed a compensation algorithm used to extract the reference currents. However, still three predictive current control models for each phase are used. Moreover, the cross-coupling terms between $d q$ axis and synchronous frame system have not been taken into account. Many other attempts are proposed and discussed several techniques in order to improve the efficiency and the performance of APF [24-35]. In [36], Vatani et al. proposed finite control set MPC based on p-q theory to control a three phase Neutral Point Clamped multi-level converter to act as a shunt APF. The predictions are used to estimate the reference current two steps ahead. Nevertheless, multi-level converters have drawbacks such as complex topologies and bulky circuitry structures, higher costs, complexity of the control system and higher active power losses.

In this paper a model based MPC for shunt APF in synchronous reference frame $d q 0$ is presented. The proposed MPC has the advantage of exhibiting faster performance due to the removal of the trajectory reference stage; which is normally adopted in conventional MPC to make the system arrive to its reference value softly. In addition, handling of the control variables in $d q 0$ space, leads to reduction of the required number of current controllers to two instead of three. Moreover, $d q 0$ transformation allows for the control procedure to proceed with constant quantities instead of time variant quantities.

The input stage of the MPC is the $d q$ synchronous reference frame harmonic current and the output stage is synchronous frame harmonic current commands which are the input commands to the space vector pulse width modulation (SVPWM) generator. In this way the supply current will be equal to the fundamental component of load current and a part of the current at fundamental frequency for losses of the inverter system. A decoupling stage outputs the synchronous frame voltages which are the input commands to the SVPWM generator is utilized to let the currents injected by the filter track rapidly their references. Additionally, the dc voltage level is not need to be regulated in the proposed system.

\section{Design and Modelling of the APF with MPC}

From the shunt APF circuit connected in parallel with the electric system shown in Fig. 1, the step-wise model equations can be derived. The non-linear load draws currents $i_{L(a b c)}$ and the supply currents denotes $i_{S(a b c)}$. The APF will be supplying only the harmonic currents $\hat{i}_{(a b c)}$. The dynamic analytical model of the APF filter is

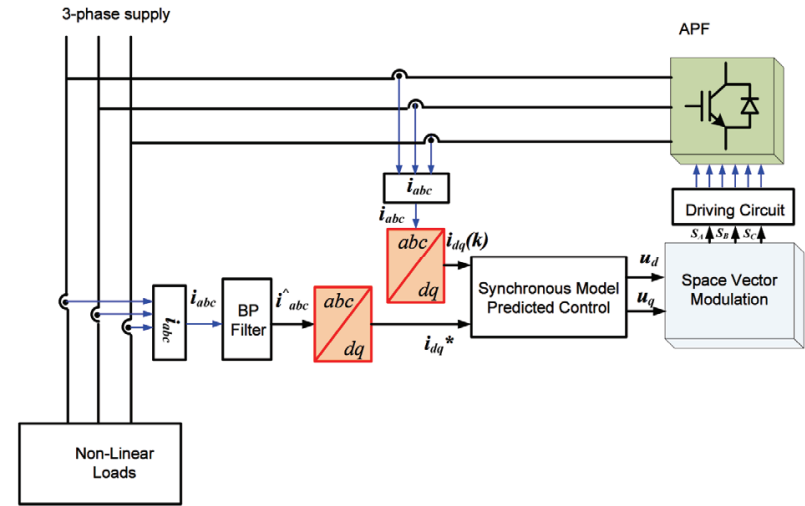

Fig. 1. Shunt active power filter connected to electric system.

developed in its original three-phase $a b c$ frame and the model is then transformed to the synchronous reference frame.

The APF system of equations can be described as:

$$
\left[\begin{array}{l}
u_{a} \\
u_{b} \\
u_{c}
\end{array}\right]=R \cdot\left[\begin{array}{l}
\hat{i}_{a} \\
\hat{i}_{b} \\
\hat{i}_{c}
\end{array}\right]+L \cdot \frac{d}{d t}\left[\begin{array}{l}
\hat{i}_{a} \\
\hat{i}_{b} \\
\hat{i}_{c}
\end{array}\right]+\left[\begin{array}{c}
v_{a} \\
v_{b} \\
v_{c}
\end{array}\right]
$$

where $v_{a b c}$ and $u_{a b c}$ are the source and APF voltages, respectively. $R$ and $L$ are the smoothing inductor inductance and resistance.

Transforming the above currents in synchronous reference frame using the transformation matrix:

$$
T_{d q 0}=\left[\begin{array}{lll}
\cos (\omega t) & \cos (\omega t+2 \pi / 3) & \cos (\omega t-2 \pi / 3) \\
\sin (\omega t) & \sin (\omega t+2 \pi / 3) & \sin (\omega t-2 \pi / 3) \\
1 / 2 & 1 / 2 & 1 / 2
\end{array}\right]
$$

where $u_{d q 0}$ could be obtained from

$$
\left[\begin{array}{l}
u_{d} \\
u_{q} \\
u_{0}
\end{array}\right]=\frac{2}{3} \quad T_{d q 0}\left[\begin{array}{l}
\mathrm{u}_{\mathrm{a}} \\
\mathrm{u}_{\mathrm{b}} \\
\mathrm{u}_{\mathrm{c}}
\end{array}\right]
$$

Hence, $u_{d q 0}$ is found for the three-phase system to be

$$
\left[\begin{array}{l}
u_{d} \\
u_{q} \\
u_{0}
\end{array}\right]=R \cdot\left[\begin{array}{l}
i_{d} \\
i_{q} \\
i_{0}
\end{array}\right]+\omega L \cdot\left[\begin{array}{l}
-i_{q} \\
i_{d} \\
i_{0}
\end{array}\right]+L \cdot \frac{d}{d t}\left[\begin{array}{l}
i_{d} \\
i_{q} \\
i_{0}
\end{array}\right]+\left[\begin{array}{l}
v_{d} \\
v_{q} \\
v_{0}
\end{array}\right]
$$

\subsection{Modeling synchronous predictive controller}

In order to obtain a closed loop mathematical form for the controller, discretizing Eq. (4) becomes necessary as in 


$$
\begin{gathered}
{\left[\begin{array}{l}
u_{d}(k) \\
u_{q}(k) \\
u_{0}(k)
\end{array}\right]=R \cdot\left[\begin{array}{l}
i_{d}(k) \\
i_{q}(k) \\
i_{0}(k)
\end{array}\right]+\omega L \cdot\left[\begin{array}{l}
-i_{q}(k) \\
i_{d}(k) \\
i_{0}(k)
\end{array}\right] \ldots} \\
\ldots+\frac{L}{T_{s}} \cdot\left[\begin{array}{l}
i_{d}(k)-i_{d}(k-1) \\
i_{q}(k)-i_{q}(k-1) \\
i_{0}(k)-i_{0}(k-1)
\end{array}\right]+\left[\begin{array}{l}
v_{d}(k) \\
v_{q}(k) \\
v_{0}(k)
\end{array}\right]
\end{gathered}
$$

Assuming a three-phase balanced power source, the $v_{d q 0}$ term can be removed from Eq. (5)

$$
\begin{gathered}
{\left[\begin{array}{l}
u_{d}(k) \\
u_{q}(k) \\
u_{0}(k)
\end{array}\right]=\left(\frac{R \cdot T_{s}+L}{T_{s}} \cdot\left[\begin{array}{l}
i_{d}(k) \\
i_{q}(k) \\
i_{0}(k)
\end{array}\right]+\omega L \cdot\left[\begin{array}{l}
-i_{q}(k) \\
i_{d}(k) \\
i_{0}(k)
\end{array}\right] \ldots\right.} \\
\ldots-\frac{L}{T_{s}} \cdot\left[\begin{array}{c}
i_{d}(k-1) \\
i_{q}(k-1) \\
i_{0}(k-1)
\end{array}\right]
\end{gathered}
$$

Hence, solving Eq. (6) for $v_{d q 0}$ and replacing $k=k+1$ results in the predictive system of equations

$\left[\begin{array}{l}i_{d}(k+1) \\ i_{q}(k+1) \\ i_{0}(k+1)\end{array}\right]=\alpha \cdot\left[\begin{array}{l}u_{d}(k+1) \\ u_{q}(k+1) \\ u_{0}(k+1)\end{array}\right]-\phi \cdot\left[\begin{array}{l}-i_{q}(k+1) \\ i_{d}(k+1) \\ i_{0}(k+1)\end{array}\right]+\beta \cdot\left[\begin{array}{l}i_{d}(k) \\ i_{q}(k) \\ i_{0}(k)\end{array}\right]$

where $\alpha=\frac{T_{s}}{R \cdot T_{s}+L}$ and $\beta=\frac{L}{R \cdot T_{s}+L}$ and the middle term associated with $\phi=\frac{\omega L T_{s}}{R \cdot T_{s}+L}$ is the cross-coupling term between the $d$ and $q$ axis, and it acts as a feedback loop between them. The first order differential equation for the APF model is used as the predictive current controller without the source disturbance. The single step predictive model of the active power filter output current in synchronous reference frame is reduced to $d$ and $d$ components for a balanced three phase system.

The cross-coupling term after manipulation turns into an angular coefficient labeled cross-coupling angular correction and expressed as

$$
\phi=2 \pi \cdot \frac{T_{s} / T_{f}}{T_{s} / \hat{\tau}+1}
$$

Where $T_{f}$ is the fundamental frequency and $\tau$ is the RL time constant. It is noted here that in the predictive control and error correction, $\hat{\tau}=\tau \cdot \tau_{e r}$, where $\tau_{e r}$ is the error coefficient in the time constant.

\subsection{Controller feedback correction}

In MPC modelling, feedback correction is necessary to account for the drift in the predictive model equations due to the non-linear nature of the APF. Therefore, an error $e(k)$ is added to the output current of the APF to account for such discrepancy.

$$
\tilde{i}_{d q 0}(k+1)=i_{d q 0}(k+1)+\delta e(k)
$$

where the error is calculated as the difference between the actual current at $k$ and the predicted current $i_{d q 0}$ at the same discrete instance. Where $\delta$ is the correction coefficient. The reference trajectory block is necessary for applications that requires the output to arrive at reference values softly. While in APF implementation, this is omitted as the predictive controller is required to quickly respond to reference commands and is required to fast track any changes in the reference values.

\subsection{Controller dynamic optimization}

MPC dynamic optimization requires an objective function that will track changes in the commands online. The weighted quadratic performance index is commonly used in dynamic optimization as its objective function and expressed as

$$
J=q\left[\tilde{i}_{d q 0}(k+1)-i_{d q 0}^{*}(k+1)\right]^{2}+\lambda \cdot u_{d q 0}^{2}(k+1)
$$

where the parameters $q$ is the weighting coefficient of the predictive error and $\lambda$ is the predictive control variable. It is noted that the control variables of the APF are its voltage $u_{d q 0}$ and are set as the input commands to the APF. The optimal performance of the controller can be achieved by differentiating the objective function $J$ with respect to the voltage comaned and equating that to zero $(d J / d u=0)$.

$$
\begin{aligned}
J= & q\left[\tilde{i}_{d q 0}(k+1)-i_{d q 0}^{*}(k+1)\right]^{2}+\lambda \cdot u_{d q 0}^{2}(k+1) \\
J= & q\left[\tilde{i}_{d q 0}^{2}(k+1)-2 \cdot \tilde{i}_{d q 0}(k+1) \cdot i_{d q 0}^{*}(k+1)\right. \\
& \left.\ldots-i_{d q 0}^{* 2}(k+1)\right]+\lambda \cdot u_{d q 0}^{2}(k+1) \\
J= & q\left[\left(i_{d q 0}(k+1)+\delta e(k)\right)^{2}-2 \cdot\left(i_{d q 0}(k+1)\right.\right. \\
& \cdots+\delta e(k)) \cdot i_{d q 0}^{*}(k+1) \\
& \left.\cdots+i_{d q 0}^{*_{2}}(k+1)\right]+\lambda \cdot u_{d q 0}^{2}(k+1)
\end{aligned}
$$

where

$$
i_{d q 0}(k+1)=\alpha \cdot u_{d q 0}(k+1)-\phi \cdot i_{q d 0}(k) \cdots-\beta \cdot i_{d q 0}(k)
$$
(16)

After substitution, $d J / d u_{d q 0}=0$, it can be found to be

$$
u_{d q 0}(k+1)=\frac{\alpha \cdot q}{\lambda+\alpha^{2} \cdot q}\left[i_{d q 0}^{*}(k+1) \cdots-\beta \cdot i_{d q 0}(k)-e(k)\right]
$$

Fig. 2 debicts the block diagram of the proposed MPC. 


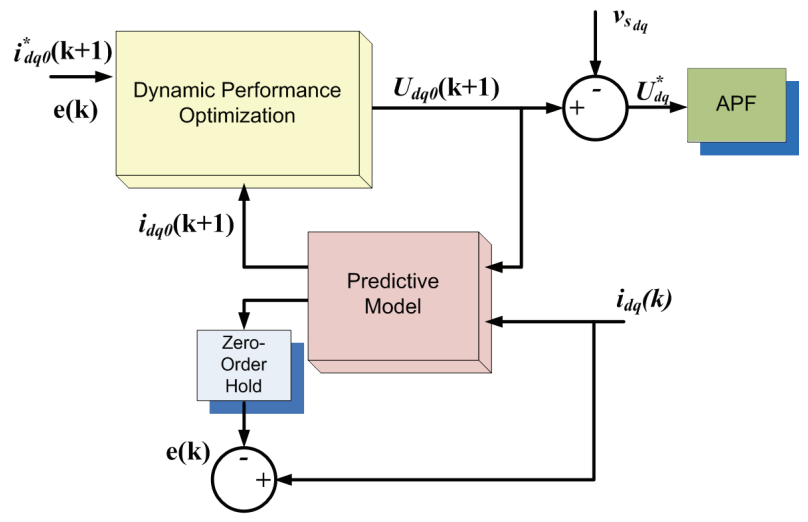

Fig. 2. Predictive controller for the APF

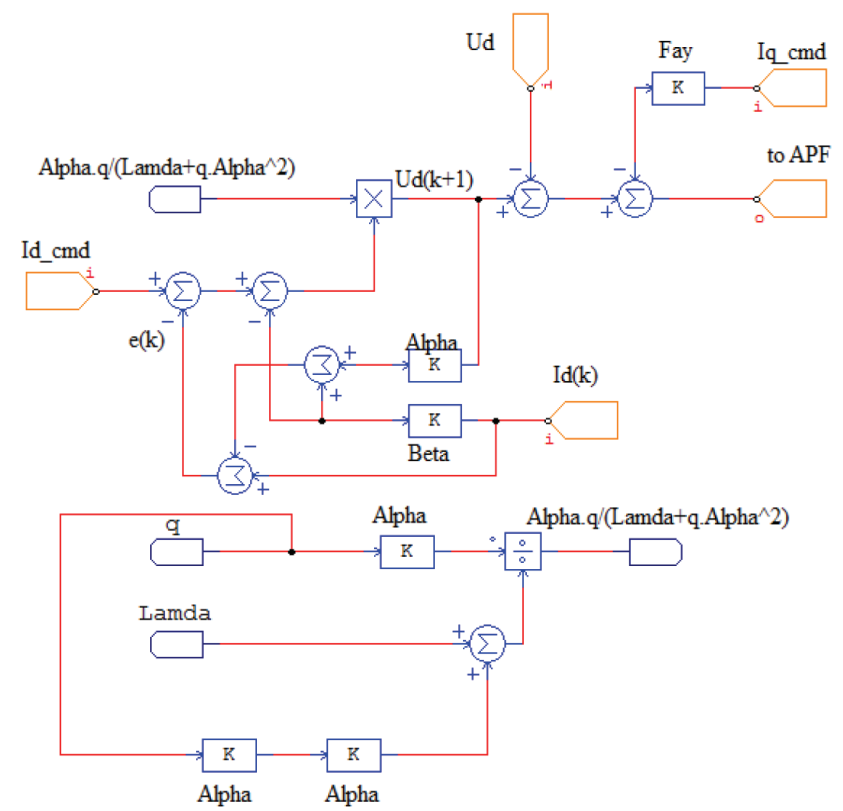

Fig. 3. Block diagram of MPC for simulation and practical implementation.

Implementaion of the controller is fairlly easy. The voltage at the point of the filter connection is considered as a disturbance and omitted by the closed loop. The colsed loop consists of feedback correction and dynamic optimization. Therefore, no voltage sensors are required by the MPC controller. Hence, cost reduction is is likely attained. Furthermore, calculating the control variables of the next sampling, at instant $k+1$, is carried out at instent $k$, that enables rapid tracking and fast dynamic reponce.

\subsection{Controller design parameters}

The model predictive controller is realized as in Fig. 3. The values for the resistance and inductance used are 0.225 $\Omega$ and $2 \mathrm{mH}$ respectively, which results in:

$$
\begin{gathered}
\alpha=4.94 \mathrm{E}^{-02} \\
\beta=9.89 \mathrm{E}^{-01} \\
\phi=3.73 \mathrm{E}^{-02} \mathrm{rad} / \mathrm{s}
\end{gathered}
$$

The dynamic optimization parameters $(\lambda, q)$ were chosen after an in depth evaluation as in [22] and after a number of trial and evaluation attempts, a value of $\lambda=1$ and $q=5000$ is selected which allows fast tracking of the command signal with relatively minimal ripple.

The final block diagram of the simulation and practical implementation of proposed MPC for shunt APF is illustrated in Fig. 3.

\section{Simulation Results}

Implementation of the proposed MPC for APF in synchronous reference frame has been carried out in PSIM software to study the performance of the proposed control

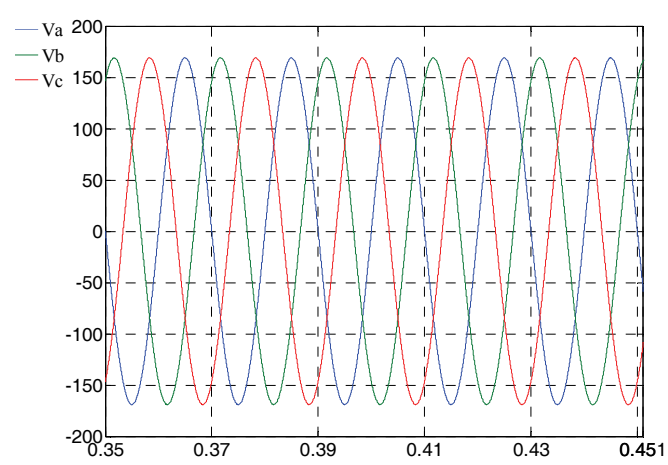

(a) Grid voltages

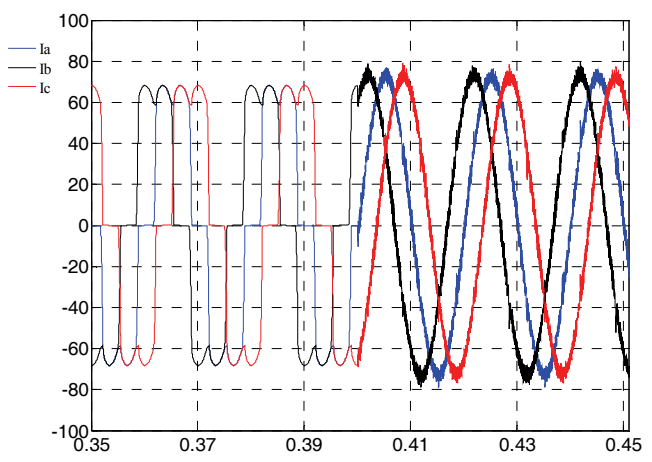

(b) Three-phase grid currents

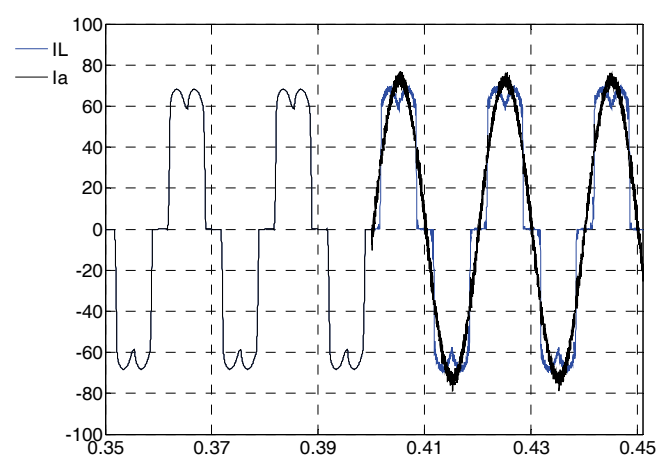

(c) Phase A currents

Fig. 4. Grid Voltages and currents during APF connection 
strategy. The feasibility of the suggested predictive current control is verified through simulation results under steady state and transient conditions for non-linear load. The simulation results will be discussed in the following:

The command current was obtained by sampling the load current including harmonics and then subtracting the fundamental desired current, resulting in the harmonic contents required to be removed. Fig. 4 shows the grid voltage and currents with and without APF. The simulation was started at $t=0.0 \mathrm{~s}$, where the APF was turned off between $0<\mathrm{t}<0.4 \mathrm{~s}$. During this period of time, the current supplied by the grid is the nonlinear load current, which is non sinusoidal and includes harmonic contents. At $t=0.4 \mathrm{~s}$ the active power filter is turned on. During this period, the APF samples the grid current and supplies the appropriate harmonic currents required by the nonlinear load. After $\mathrm{t}=0.4 \mathrm{~s}$, the grid currents are shown to be sinusoidal at the operating point of $50 \mathrm{~A} \mathrm{rms}$. The harmonic contents in the grid currents are nearly eliminated and the grid currents become almost sinusoidal as shown in Fig. 4(b). The grid currents for a step change in the nonlinear load current at $\mathrm{t}=0.8 \mathrm{sec}$. is illustrated in Fig. 4(c), which shows a fast dynamic response of the proposed MPC.

The function of the APF predictive controller is investigated under a step change in the non-linear load profile. A step change in the load current is introduced at $t=0.8 \mathrm{~s}$ is shown in Fig. 5. As it can be seen from the Fig. 5(a), the three-phase grid currents move toward the new operating point of $105 \mathrm{~A}$ rms. The grid currents remain sinusoidal as

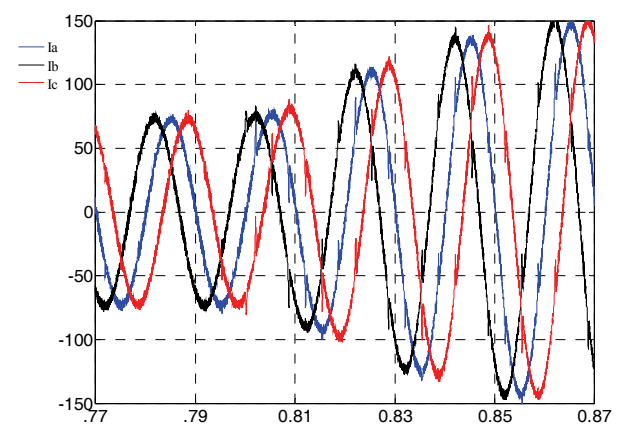

(a) Three-phase grid currents

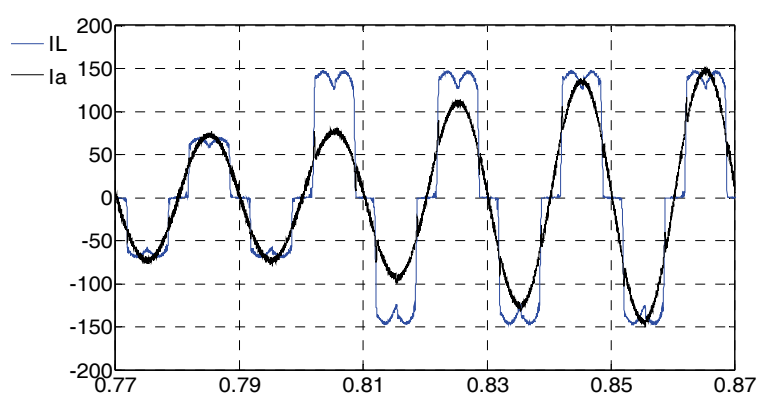

(b) Phase A currents

Fig. 5. Grid currents at step change in load. the predictive controller of the APF dynamically adjusts to the new operating point. It can be seen here that the predictive controller is able to handle a step change and adjusts for the new operation conditions to reach steady state values within three cycles. It also instantaneously supplies the required harmonics on demand and partial fundamental current during the sudden load change. This means, the APF acts as a smoother for the grid current during the sudden change in operating point. As it can be seen, the grid current remains sinusoidal and within $0.048 \mathrm{sec}$ meets the required current. During this process, the APF supplies the harmonic current component required by the load in addition to a transitional component of the fundamental current. In this case, no harmonic component exhibited by the grid and the function of the active power filter fulfills the requirement of the step change in load. It is worthy to note that this particular APF is designed to meet the power requirement of this specific application.

To illustrate the fast performance characteristics of the predictive controller of the APF, Fig. 6(a) shows the load harmonic component and active power filter currents. Between $0<\mathrm{t}<0.4 \mathrm{~s}$, it can be seen that the APF is disconnected and the load currents including its harmonic contents are totally supplied by the grid. After $t=0.4 \mathrm{~s}$, the APF is connected and instantly tracks the harmonic component of the load. At $\mathrm{t}=0.8 \mathrm{~s}$ a step change in the load occurs and Fig. 6(b) shows the APF controller compensation for the sudden change in load requirement and in addition, it transitions the grid current into its new

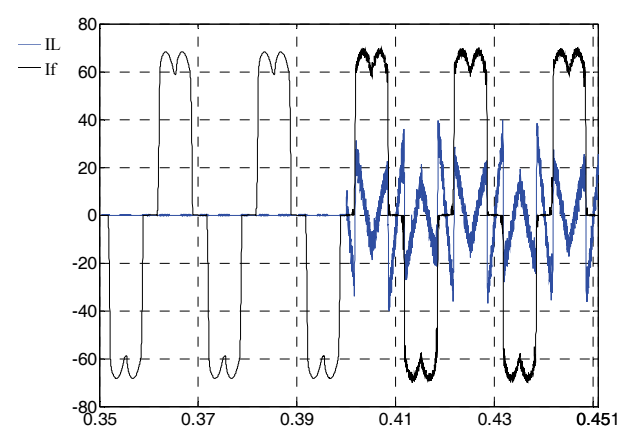

(a) APF switched on

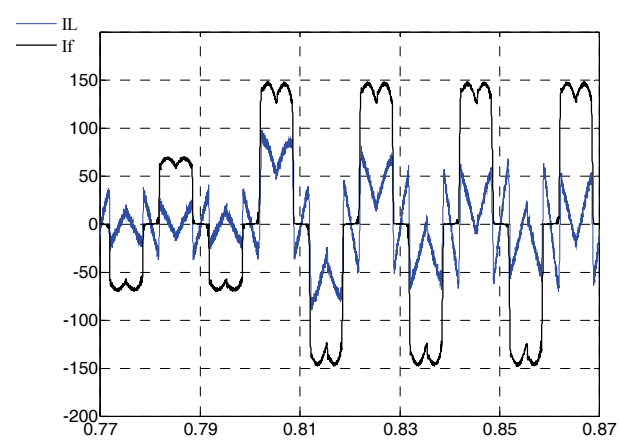

(b) load change

Fig. 6. APF and load currents. 


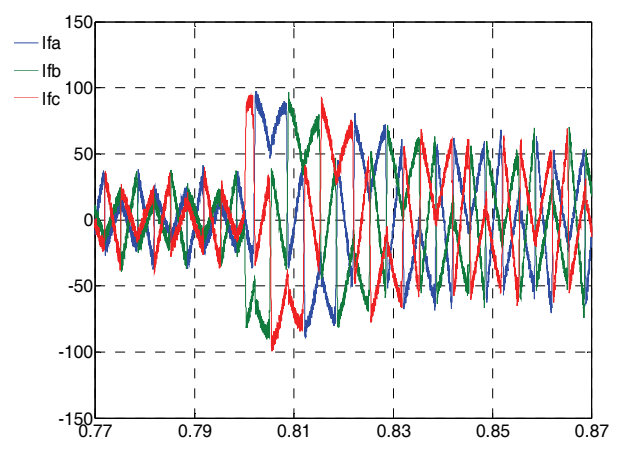

(a) Three-phase APF injected currents, load change

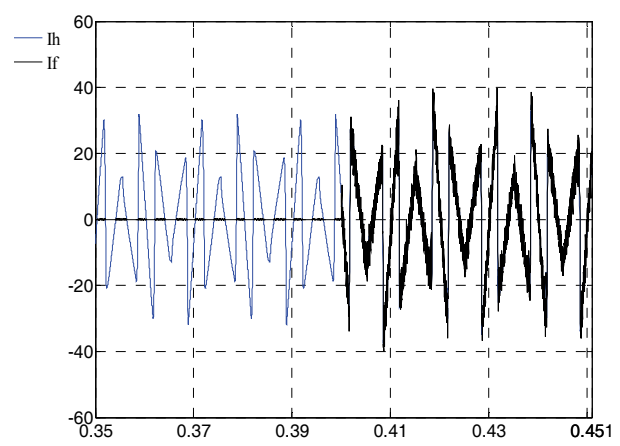

(b) Phase A currents, APF switched on

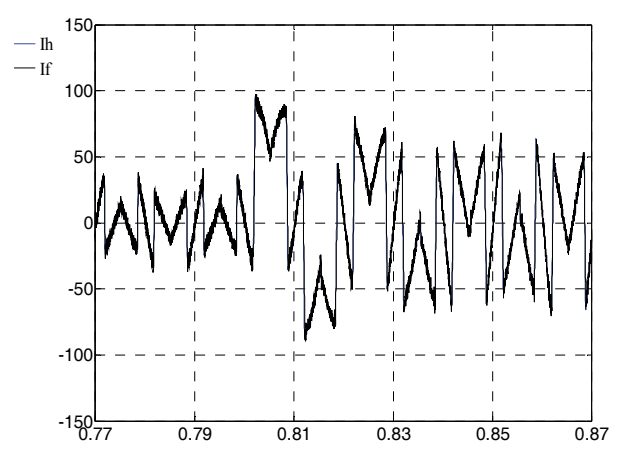

(c) Phase A currents, load change

Fig. 7. Active power filter injected currents tracking capability.

operating point without any major disturbance or noise, see Fig. 5.

In parallel to the grid current above, Fig. 7 shows onephase of the APF injected currents for the same particular periods. It is worth mentioning here that the APF tracking of the harmonic components in grid currents is instantaneous. As seen from the lower part of Fig. 7, the APF supplies both the fundamental and harmonic current during next three cycles after the step change in load current.

Fig. 8 shows the harmonic contents of the grid current (Phase A) before and after the APF connection. Before the filter connection, the THD content was $\% 20$ while the active power filter reduced the content for the same period to less than $\% 5$.
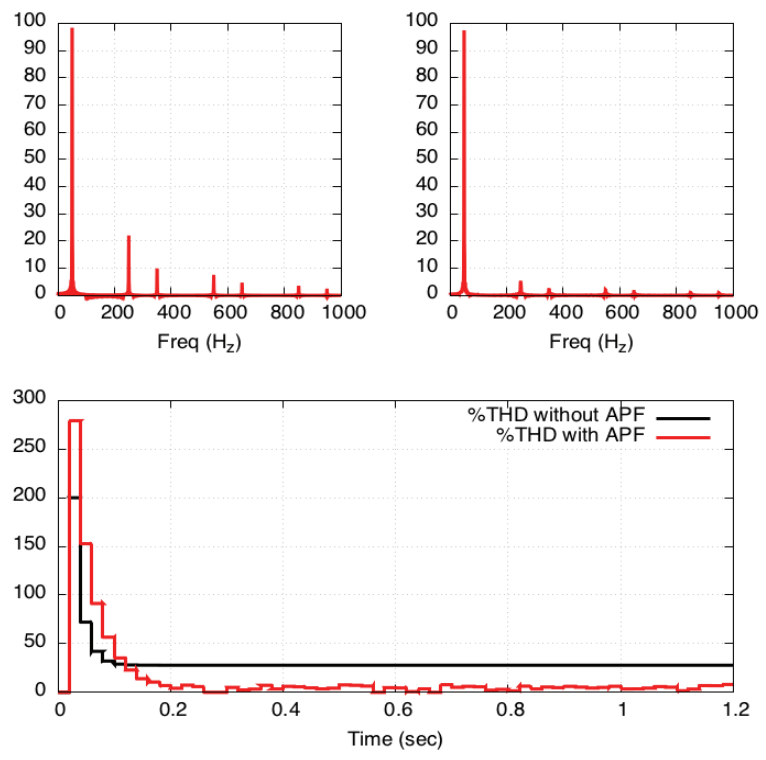

Fig. 8. Total harmonic distortion content in grid current.

\section{Experimental results}

The performance of the proposed active power filter is verified experimentally with the configuration shown in Fig. 9. The experimental platform consists of grid emulator to supply the nonlinear load, three phase dc/ac SVPWM inverter acting as APF with a $10 \mathrm{KHz}$ switching frequency to generate and inject the required harmonics. A dSPACE DS1103-based digital signal processor is used to generate the gating signals and implement the proposed control scheme. The APF is practically implemented using sing Powerex CM150TX-24 intelligent power module (IGBT) produced by Mitsubishi Co. Ltd. The nonlinear load is represented by a three-phase full wave diode-bridge rectifier using 6RI75G-120 by Fuji Electric with resistive load. The grid voltages are measured using CYVS411D07380V-6_01 high accuracy AC voltage sensors. Two sets of three CYCS411D47-8A-5 high accuracy AC current sensors are used for measuring the load and the APF injected currents. A DSO7104A Agilent digital oscilloscope is used to display and capture the output waveforms and a Fluke 43B power quality analyzer is used for harmonic calculations. The dSPACE DS1103 controller board provides a real-time interface (RTI) between the hardware and the computer model created in Matlab Simulink.

A prototype of power rating of $2 \mathrm{~kW}$ is practically examined and the experimental results will be discussed in the following. Fig. 9 demonstrates the overall appearance of the experimental setup with the design specifications and circuit parameters used in the simulation and experimental tests are listed in Table 1.

The distorted load current of non-linear load of threephase diode-bridge rectifier is compared with its fundamental signal to generate the required feedback signalof the 
Table 1. Design specifications and circuit constants

\begin{tabular}{c|c|c}
\hline Parameter & Symbol & Value \\
\hline Power rating & $K V A$ & $1.5 \mathrm{KVA}$ \\
\hline Grid voltage & $V_{s m}$ & $110 \mathrm{~V}$ \\
\hline Rated current & $I$ & $8 \mathrm{~A}$ \\
\hline Supply frequency & $f_{s}$ & $50 \mathrm{HZ}$ \\
\hline Switching frequency & $f_{c}$ & $10 \mathrm{kHZ}$ \\
\hline Load resistance & $R_{L}$ & $\Omega 20$ \\
\hline Coupling inductor & $L$ & $1 \mathrm{mH}$ \\
\hline Dead time & $t_{d}$ & $\mu 3 \mathrm{Sec}$ \\
\hline Inverter & Powerex IGBT CM150TX-24 \\
\hline Diode-bridge rectifier & \multicolumn{2}{|c}{ 6RI75G-120 } \\
\hline Current sensors & \multicolumn{2}{|c}{ CYCS411D47-8A-5 } \\
\hline Voltage sensors & CYVS411D07-380V-6_01
\end{tabular}

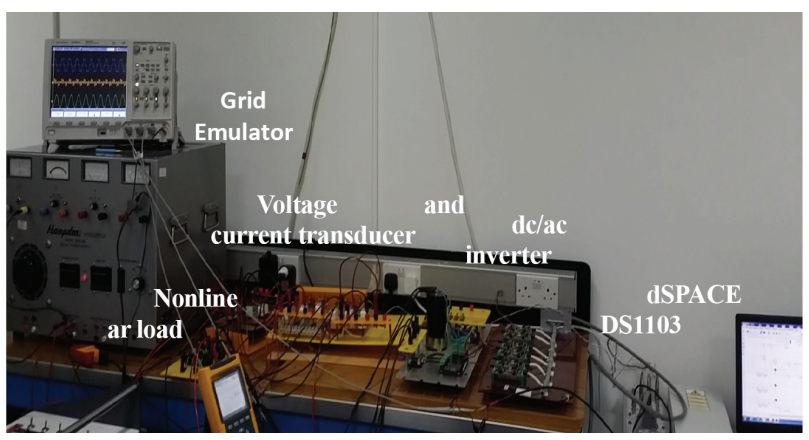

Fig. 9. Test rig photograph

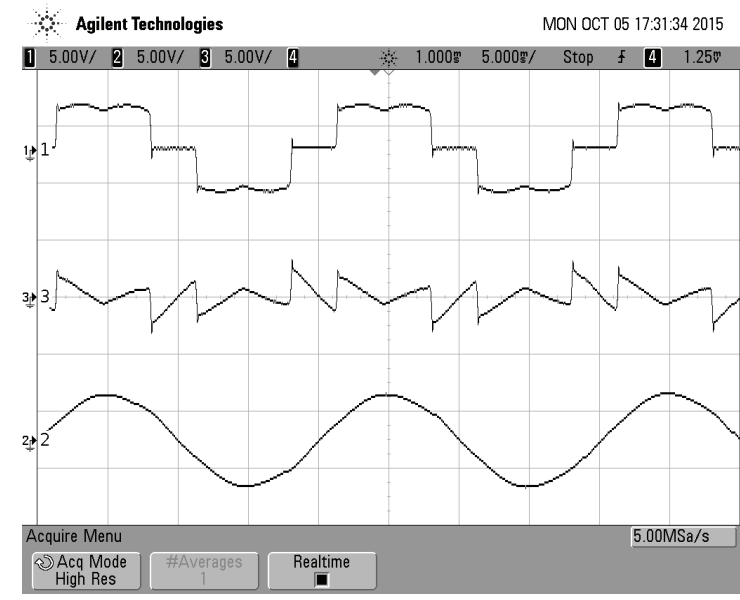

Fig. 10. The load current (upper trace), its harmonics (middle) and fundamental component (lower)

proposed controller.

Fig. 10 shows a phase A distorted load current along with its harmonic contents and its fundamental component. The shunt active power filter is connected with the series reactor to eliminate the grid current harmonics. Fig. 11 shows the three-phase load currents, APF injected currents and grid currents.

Fig. 12 shows the wafeforms of three-phase grid currents at a step change in load, which reflects the rapid tracking performance and fast dynamic reponse of proposed MPC controller under sudden load change. The transition to new

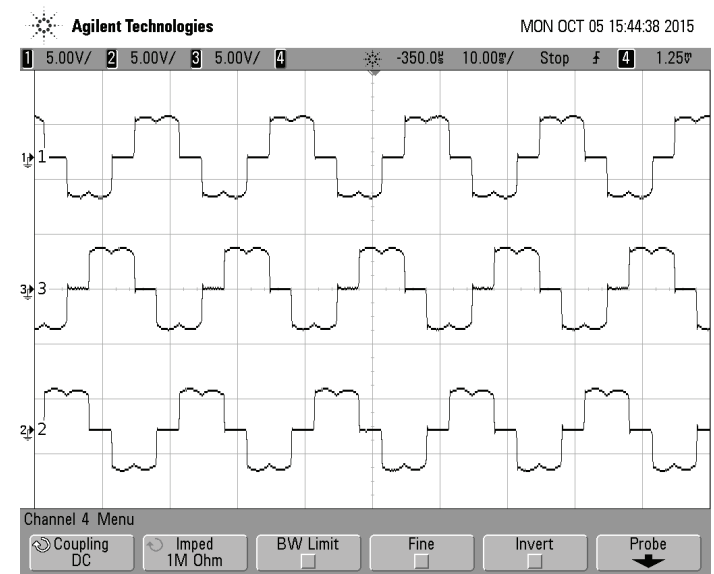

(a) Load currents

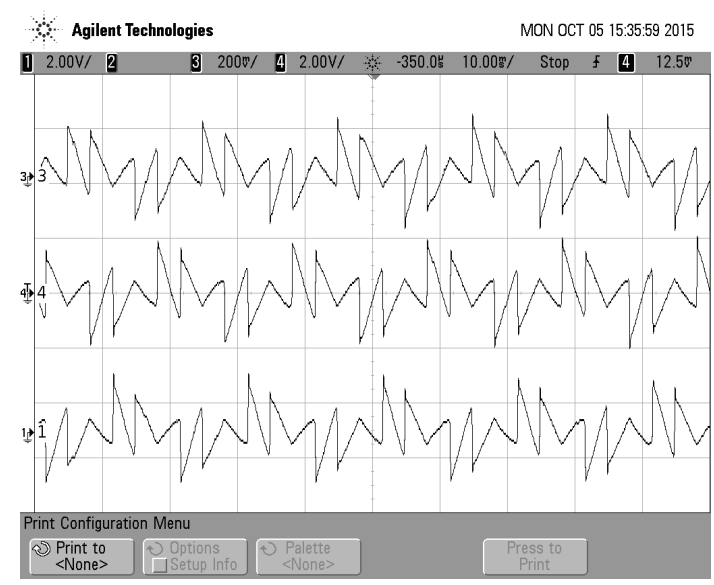

(b) APF injected currents

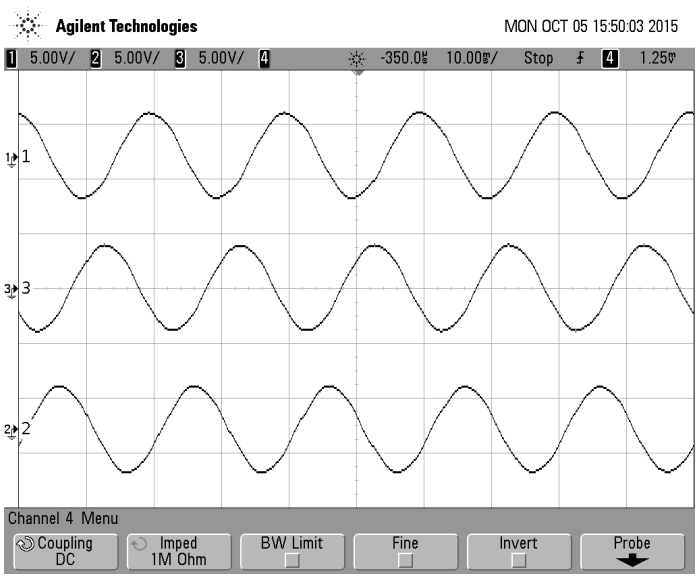

(c) Grid currents

Fig. 11. Three phase system currents

operating point appears smooth due to the interaction of the APF which is responsible for eliminating the harmonic currents in addition to ensuring soft transition of the grid current fundamental value to the new operating point without any undesired harmonic components.

Fig. 13 shows the grid voltage and current, phase A. It is 


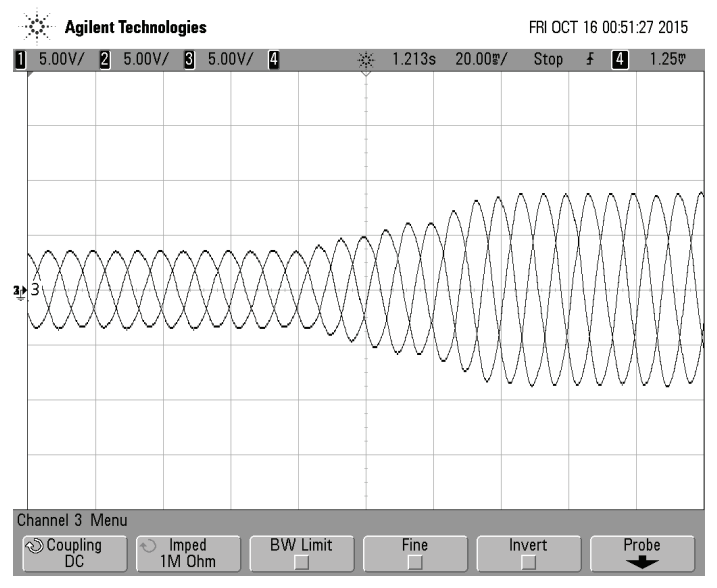

(a) Step up in load

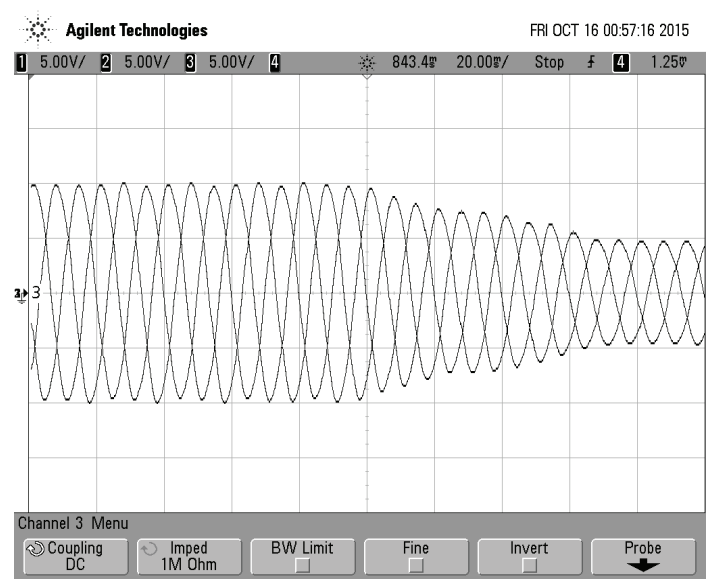

(b) Step down in load

Fig. 12. Three-phase grid currents at step change in load.

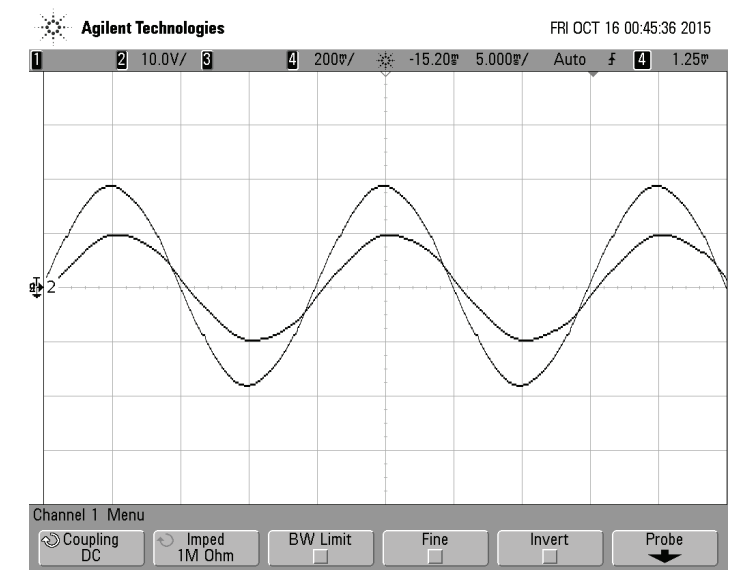

Fig. 13. Grid voltage and current, phase A

clear to obvious that the grid current become sinusoidal and in phase with the grid voltage.

Harmonic spectrums of the grid current before and after connecting the proposed MPC for APF are shown in Figs. 14(a) and (b), respectively. The total harmonic distortion

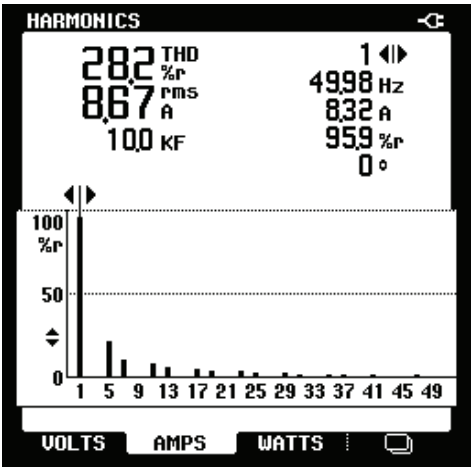

(a) Harmonic spectrum before connecting the APF

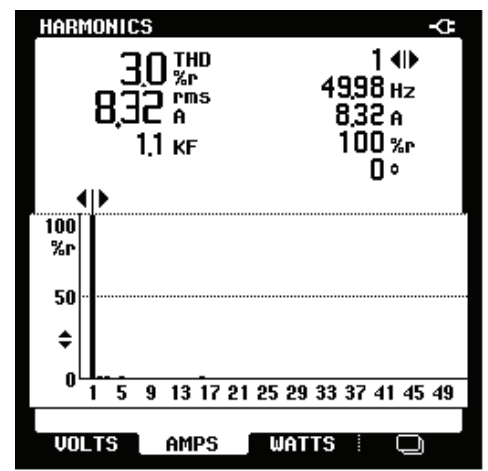

(b) Harmonic spectrum after connecting the APF

Fig. 14. Harmonic spectrum of the grid current

(THD) in the grid current is computed and it is found to be $28.2 \%$ before harmonic compensation and 3\% after harmonic current compensation that is that means a highquality sinusoidal waveforms within the limit of the of 519 IEEE harmonic standard of grid current is obtained using the proposed APF.

\section{Conclusion}

A predictive current control for a three-phase three wire current source shunt active power filter has been presented in this paper. The control approach uses the predicted value of the direct and quadrature error in synchronous reference frame and the optimal switching state to be applied to the next sampling time is selected to control the inverter with minimum switching frequency while maintaining fast harmonic compensation. Moreover, this control approach does not require supply voltage sensing, which generally reduces the system complexity. Mathematical analyses have been presented and simulation results are performed under steady state and transient conditions for non-linear loads to validate the theoretical development and confirm the performance of proposed approach. The presented simulation results indicate that the presented control approach provides fast dynamic response and good tracking of the harmonic compensation to its reference 
value. The proposed predictive current control is simple and very easy to implement compared to classical PWM techniques. As assessment comparing both predictive and classical PI control techniques is considered for a future study, as well the operation at unity input power factor, allowing harmonic current compensation and reactive power compensation.

\section{Acknowledgements}

This project was supported in full by the Public Authority of Applied Education \& Training, Kuwait. Project \# TS-13-05.

\section{References}

[1] B. K. Bose, "Energy, environment, and advances in power electronics," in Industrial Electronics, 2000. ISIE 2000. Proceedings of the 2000 IEEE International Symposium on, 2000.

[2] H. Bittencourt, G. L. Tavares and L. Lopes, "Investigation and Mitigation of the Amplification of the Harmonic Current to the Filtering System of an Aluminum Smelter," Proc. of the oceedings of the 6th WSEAS Int. Conference on Power Systems, Lisbon, Portugal, September pp. 183-188, sep. 2006.

[3] X. Wu, S. K. Panda, and J. Xu, "Analysis and Control of the Output Instantaneous Power for Three Phase PWM Boost Rectifier Under Unbalanced Supply Voltage Conditions," The IEEE 32nd Annual Ind. Electron Conference, IECON 2006- , pp. 1-6, 2006.

[4] M. Maksić, D. Matvoz, J. Kosmač, and I. Papič, "Circuit breaker switching transients at arc furnace installation," Proc. of Int. Conference on Power Systems Transients (IPST2009), Kyoto, Japan June 3-6, 2009

[5] Z. Li, Y. Li, P. Wang, H. Zhu, C. Liu, and W. Xu, "Control of Three-Phase Boost-Type PWM Rectifier in Stationary Frame Under Unbalanced Input Voltage," IEEE Trans. Power Electron., vol. 25, no. 10, pp. 2521-2530, 2010.

[6] S. Chacko and N. Goel, "Voltage Sag mitigation in Electric Arc Furnace with D-STATCOM," Int. Electrical Engineering Journal (IEEJ), vol. 2, no. 2, pp. 536-542, 2011.

[7] "IEEE Trial-Use Standard Definitions for the Measurement of Electric Power Quantities Under Sinusoidal, Non-sinusoidal, Balanced, or Unbalanced Conditions," IEEE Std 1459-2000, 2000.

[8] E. Emanuel, "Summary of IEEE standard 1459: definitions for the measurement of electric power quantities under sinusoidal, nonsinusoidal, balanced, or unbalanced conditions," IEEE Trans. Ind. Appl., vol. 40, no. 3, pp. 869-876, May-June 2004.

[9] D. Rivas, L. Moran, L.W. Dixon, and J. R. Espinoza, "Improving passive filter compensation performance with active techniques," IEEE Trans. Ind. Electron., vol. 50, no. 1, pp. 161-170, Feb. 2003.

[10] C. Panoiu, I. Baciu, M. Panoiu, and C. Cuntan, "Simulation results on the currents harmonics mitigation on the railway station line feed using a data acquisition system," WSEAS Trans. on Electron., vol. 4, no. 10, October 2007.

[11] D. D. Reljic, V. V. Vasic, and D. V. Oros, "Power factor correction and harmonics mitigation based on phase shifting approach," in Power Electronics and Motion Control Conference (EPE/PEMC), $201215^{\text {th }}$ International, 2012.

[12] M. F. Schlecht and B. A. Miwa, "Active power factor correction for switching power supplies," IEEE Trans. Power Electronics, vol. 2, no. 4, pp. 273, 281, Oct. 1987.

[13] H. Akagi, Y. Kanazawa, and A. Nabae, "Instantaneous Reactive Power Compensators Comprising Switching Devices without Energy Storage Components," IEEE Trans. Ind. Appl., vol. 20, no. 3, pp. 625-630, May 1984.

[14] M. El-Habrouk, M. K. Darwish, and P. Mehta, "Active power filters: a review," Proc. of IEE Electric Power Applic. vol. 147, no. 5, pp. 403, 413, Sep. 2000.

[15] E. Ozdemir, M. Ucar, M. Kesler, and M. Kale, "A Simplified Control Algorithm for Shunt Active Power Filter Without Load and Filter Current Measurement," Proc. of the 32nd IEEE Ind. Electron Annual Conference IECON 2006, pp. 2599-2604, Nov.2006.

[16] J. Chen, F. Liu, and S. Mei, "Passivity-based H/sub/ spl infin//control for APF in three-phase four-wire distribution power systems," IEEE Power Engineering Society General Meeting, Montreal, Canada, 2006.

[17] H. Rui, W. Jian, H. Zhihao, X. Dianguo, and H. Ke, "A research on control strategy of APF combined with TSC," Proc. of the 7th Int. Power Electron. and Motion Control Conference (IPEMC), pp. 28142818, 2012.

[18] F. Shaosheng and W. Yaonan, "Fuzzy model predictive control for active power filter," Electric Utility Deregulation, Restructuring and Power Technologies, 2004. (DRPT 2004). Proc. of the 2004 IEEE Int. Conference, vol. 1, no. 5-8, pp. 295-300, Apr. 2004.

[19] W. Xuhong and H. Yigang, "Fuzzy Neural Network based Predictive Control for Active Power Filter," Proc. of Int. Power System Technology Conference, PowerCon 2006. pp. 1-5, Oct. 2006.

[20] R. Mohanty and A. K. Kapoor, "Performance evaluation of HCC \& SVPWM current controllers for shunt APF under fault conditions," Proc. of Int. conference on Power Electronics (IICPE), pp.1,8, 
28-30 Jan. 2011.

[21] N. Mendalek and K. Al-Haddad, "Modeling and nonlinear control of shunt active power filter in the synchronous reference frame," Proc. of Ninth Int. Conference in Harmonics and Quality of Power, pp. 30-35, vol.1, pp.30,35 vol.1, Orlando, USA, 2000.

[22] W. Xiao-gang, X. Yun-xiang, and S. Ding-xin, "Simplified model predictive control for a shunt active power filter," Proc. of IEEE Power Electron. Specialists Conference, PESC, pp. 3279-3283, 2008.

[23] S. da Silva, A. F. Neto, S. Cervantes, A. Goedtel, and C. F. Nascimento, "Synchronous reference frame based controllers applied to shunt active power filters in three-phase four-wire systems," Proc. of IEE of Industrial Technology (ICIT), pp. 832-837, Mar. 2010.

[24] Haithem Abu-Rub,Jaroslaw Guzin'ski, Zbigniew Krzeminski, and Hamid A. Toliyat, "Predictive Current Control of Voltage-Source Inverters", IEEE Trans. Ind. Electron., Vol. 51, no. 3, pp. 585-591, June 2004.

[25] Patricio Cortés, Marian P. Kazmierkowski, Ralph M. Kennel, Daniel E. Quevedo, and José Rodríguez, "Predictive Control in Power Electronics and Drives", IEEE Trans. Ind. Electron., Vol. 55, no.12, pp. 4312-4324, Dec., 2008.

[26] Q. Zeng and L. Chang, "An advanced SVPWMbased predictive current controller for three-phase inverters in distributed generation systems," IEEE Trans. Ind. Electron., vol. 55, no. 3, pp. 1235-1246, March. 2008.

[27] P. Zanchetta, D. B. Gerry, V. G. Monopoli, J. C. Clare, and P.W. Wheeler, "Predictive current control for multilevel active rectifiers with reduced switching frequency," IEEE Trans. Ind. Electron., vol. 55, no. 1, pp. 163-172, Jan. 2008.

[28] M. A. Perez, P. Cortes, and J. Rodriguez, "Predictive control algorithm technique for multilevel symmetric cascaded H-bridge inverters," IEEE Trans. Ind. Electron., vol. 55, no. 12, pp. 4354-4361, Dec. 2008.

[29] G. Papafotiou, J. Kley, K.G. Papadopoulos, P. Bohren, and M. Morari.Model predictive direct torque control -part II: Implementation and experimental evaluation", IEEE Trans. Ind. Electron., Vol. 56, no. 6, pp. 19061915, Jun. 2009.

[30] M. S. Hamad, M. I. Masoud, and B. W. Williams, "Medium-Voltage 12-Pulse Converter: Output Voltage Harmonic Compensation Using a Series APF", IEEE Trans. Ind. Electron., Vol. 61, no. 1, pp. 43, 52, Jan. 2014.

[31] F. Zobaa, "Optimal Multiobjective Design of Hybrid Active Power Filters Considering a Distorted Environment," IEEE Trans. Ind. Electron., vol. 61, no. 1, pp. 107-114, Jan. 2014.

[32] C.-K. Lin, T.-H. Liu, J.-t. Yu, L.-C. Fu, and C.-F. Hsiao, "Model-Free Predictive Current Control for
Interior Permanent-Magnet Synchronous Motor Drives Based on Current Difference Detection Technique", IEEE Trans. Ind. Electron., vol. 64, no. 2, pp 667-681, Feb. 2014.

[33] J. Rodriguez, J. Pontt, C. A. Silva, P. Correa, P. Lezana, P. Cortes, and U. Ammann, "Predictive current control of a voltage source inverter," IEEE Trans. Ind. Electron., vol. 54, no. 1, pp. 495-503, Feb. 2007.

[34] P. Acuna, L. Moran, M. Rivera, J. Dixon, J.; Rodriguez, J. Improved Active Power Filter Performance for Renewable Power Generation Systems", IEEE Trans. Power Electron., Vol. 29, no. 2, pp. 687694, Feb. 2014,

[35] P. Acuna, L. Moran, M. Rivera, R. Aguilera, R. Burgos, V. G. Agelidis, "A Single-Objective Predictive Control Method for a Multivariable Single-Phase ThreeLevel NPC Converter-Based Active Power Filter", IEEE trans. Ind. Electron., vol. 62, no. 7, pp. 45984607, July 2015.

[36] M. Vatani, M. Hovd and M. Molinas, "Finite Control Set Model Predictive Control of a shunt active power filter," Proc. of Twenty-Eighth Annual IEEE Applied Power Electronics Conference and Exposition (APEC), 2013, pp. 2156-2161, USA, 2013.

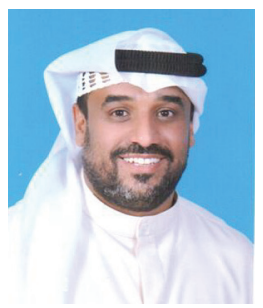

A. K. Al-Othman is an associate professor in the department of electrical engineering at the college of technological studies in Kuwait. His interests include power systems dynamics, state estimation, robust regression, evolutionary programming, application of heuristic optimization techniques to power systems and integration of renewable energy sources into power grid.

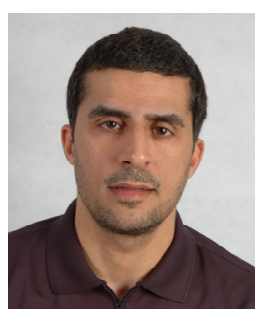

Mishel AISharidah was born in Kuwait in 1971. He received the B.S. degree from the University of Arizona (1995), M.S. degree from Portland State University (1999), and Ph.D. degree from the University of British Columbia(2012). He joined the College of Technological Studies, Shuwaikh, Kuwait, in 1999. Since 2012, he has been with the electrical engineering department where he is currently an assistant professor. His main areas of research interest are power electronics, electric vehicle motor drives, grid interconnection of distributed generation \& renewable power conditioning. Dr. AlSharidah is a member of the Institute of Electrical and Electronics Engineers of Canadian, the IEEE Power and Energy Society, and the Power Electronics Society. 


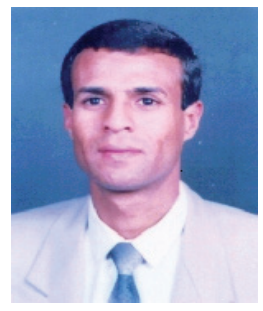

Nabil A. Ahmed received the B.Sc. and M.Sc degrees in Electrical Eng. from Assiut Univ., Egypt and the Ph.D. from the Univ. of Toyama, Japan in 1989, 1994 and 2000, respectively. Since 1989, he has been with Assiut University, where he is currently a Professor. He was a Post Doctoral fellow at the Elec. Eng. Saving Research Center, Kyungnam University, Korea from October 2004 to April 2005 and he was a JSPS post doctorate fellow at Sophia University, Japan from July 2005 to September 2006. He is now an Associate Professor at the College of Technological Studies, Public Authority of applied Education and Training, Kuwait. His research interests are in the area of power electronics, integration of renewable energy systems and soft switching converters. Prof. Ahmed is the recipient of Egypt State Encouraging of Research Prize 2005, Japan Monbusho Scholarship 1996-2000, JSPS Fellowship 20052007, best Paper Awards from ICEMS'05 and IATC'06 conferences and best Presentation award from ICEMS'04 conference. Prof. Ahmed is a member of the IEEE Industrial Electronics Society, and the Institute of Electrical of Engineering of Japan IEEJ.

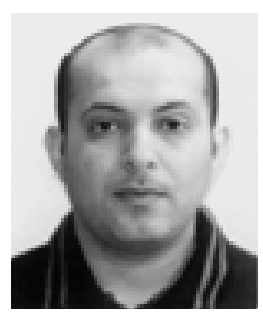

Bader N. Alajmi received the B.Sc. degree and M.Sc. from California State University, Fresno in 2001 and 2006, respectively. He received the Ph.D. degree in electrical engineering from the Electrical Department, Strathclyde University, Glasgow, UK, 2013. His research interests are digital control of power electronic systems, power quality, micro-grids, distributed generation and renewable energy. Filtering and signal processing. 